\title{
Culture As A Factor Of Intelligence Among Secondary Level Students
}

\author{
${ }^{1}$ Sidera Ijaz, ${ }^{2}$ S. Farhana Kazmi, ${ }^{3}$ Fozia Nazir \\ Sidera Ijaz, MPhil, Hazara University, KPK, Pakistan ${ }^{l}$ \\ Academic degree: Ph. D, Assistant professor, Hazara University, Mansehra, KPK, Pakistan2. \\ Fozia Nazir , Lecturer, Government Girls Degree College No.2, Mansehra, KPK, Pakistan 3
}

\begin{abstract}
Present study aimed to explore the cultural differences in intelligence. To explore the purpose simple random samples of 440 students (Urban school students $=220$, Rural school students $=220$ ) of age ranging from 12 to 15 years old was drawn from urban and rural areas of district Abbott bad KPK Pakistan. Educational level of school students was $8^{\text {th }}$ class. Survey technique was adopted for data collection. Raven's Standard Progressive matrices test was used by the researcher in face to face interview to collect the data. To evaluate the significance of results, $t$-test was applied. Results indicated that urban school students have better intellectual level as compared to rural school students. Findings also revealed the gender difference between intellectual levels of students, that showed female students have high level of non-verbal intelligence as compared to male students. Result indicated that urban male students score high on non-verbal intelligence as compare to rural male students, similarly urban female students comparatively score higher than rural female students.
\end{abstract}

Key words: Non-verbal intelligence, Urban school students, rural school students.

\section{Introduction}

Intelligence is a person's capacity to acquire knowledge, apply knowledge and engage in abstract reasoning (Boeree, 2003). Sternberg and Grigorenko (2004) argued that cultural difference can effect and even change the meaning of intelligence because behavior that consider positive in one setting proving to be negative in another culture.

Swami and Furnham (2010) indicated that urban participants have higher SAI as compared to rural participants on self-assessed intelligence (SAI).Rushton, Cvorovic and Bons (2007) found no cultural effect general factor of intelligence in Serbia but males scores high than female on matrices. Khaleefa and Lynn (2008) neither found any sex differences in test, nor in variability in Syria, however the mean IQ was lesser than that of British and the United States samples.

Fagan and Holland (2007) indicated that race was unrelated to the $g$ factor on African-Americans and Whites. Murray, Waites, Veldman, and Heatly (1973) investigated mean I.Q scores of the various ethnic groups were spread over a 15-point range with Anglos highest and blacks lowest. Diaz, Sellami, Infanzon, Lanzon and Lynn (2010) indicated that men had higher average intelligence than women, but women had greater variability than men.

Cornoldi, Belacchi, Giofre, Martini and Treaaoldi (2010) administered Raven's Progressive Colored Matrices on children belongs to South and North Italy and found no difference in IQ of both populations. Lynn, Backhoff and Contreras-Niño (2004) found no gender difference on the test, on g, or on reasoning. Powers and Barkan (1986) suggested that SPM is valid for both Hispanic and non Hispanic population.

Gardezi (2001) noted no important differences between urban and rural groups in Pakistan. Abdel-Khalek (1988) found that the SPM is a practicable instrument in the Egyptian perspective. Naderi, Abdullah, Aizan, and Sharir (2010) found no gender differences between intelligence and academic achievement. MacAvoy, Orr and Sidles (1993) indicated Raven Colored Progressive Matrices (RCPM) as a suitable tool for grade 2 and the Raven Standard Progressive Matrices (RSPM) for grades 3 through 9.

Fagan and Holland (2002) view that cultural differences in providing of information may report for racial differences in IQ. Guo, Aveyard and Dai (2009) indicated that rural and urban children were same in the means and range of scores and no cultural bias was found on Chinese Intelligence Scale for Young Children. Alexopoulos (1997) suggested that IQ of rural and urban boys are comparably high than the rural and urban girls. Rushton and Skuy (2000) found the difference between the African-Whit on the general factor of intelligence. Wysocki and Cankardas (2006) indicated that cultural background (rural \& urban), education, profession and age affect the IQ of polish adults. 
Thangavel (1986) showed that of male students has score higher as compare to female Students on Seguin Form Board Test of Intelligence. Liu and Lynn (2011) indicated that Chinese males have high IQ as compared to females and samples from United States and Japan has different IQ. Vincent and Cox (1974) point out RPM is reliable instrument for general populations and demonstrated the similar ethnic differences as found in white and black scores. Valencia (1984) point out that CPM is a suitable measure of nonverbal intelligence for different culture and languages. Borkowski and Krause (1983) theorize that differences in IQ of black and white children are due to differences in executive systems (i.e., knowledge base, control processes, and metacognitive states).

Kaniel and Fisherman (1991) found no difference between Ethiopian Jews and Israeli Jews on Progressive Matrices test. Te Nijenhuis, De Jong, Evers and van der Flier (2004) indicated the significant difference in the general factor of intelligence, academic skills and profession of Dutch and non-western immigrants (Turks, Moroccans, Surinamese, Netherlands Antilleans, and Indonesians).

Valencia (1979) found difference between both ethnic groups as Anglo group scored higher than the Chicano group. Sluis et al. (2006) investigated that females` performance was better than males on digit of symbol substitution. Herlitz and Yonker (2002) indicated that women scores high on the verbal episodic memory tasks and on face recognition as compared to male. Jausovec and Jausovec (2009) proposed that the females' have better visual event-categorization process as compared to males.

\section{Method}

Participants:The researcher selected urban and rural schools of district Abbottabad as a field of study. For the present study, total 38 urban and rural schools (19 Girls schools and 19 Boys schools) were randomly selected from urban and rural schools of Abbottabad through geographic stratification. Researcher selected the sample through simple random sampling technique by using student's attendance registers/nominal record. Every fifth student of the list was selected in a sample from the above mentioned schools (urban and rural schools). In this way 440 students with the age ranging of 12 years to 15 years were selected in a sample ( 220 boys \& 220 girls).

\section{Material and Procedure}

Raven's Standard Progressive Matrices was administered to measure nonverbal intelligence of urban and rural school students.For the data collection respondents were personally approached by the researcher and RPSM was distributed individually in face to face fashion. Clear instructions were prepared for the respondents. They were requested to go through the general instructions first and then to respond. The examinees were asked to decide about the right answer for each item with reason honestly with out cheating. The RPSM was distributed randomly to the subjects with request to complete it. Time was strictly controlled, students were asked to complete the test with in 45 minutes.

\section{Results}

Table 1

Mean, Standard Deviation and t-test of Urban and Rural Students (overall) on Non-verbal Intelligence

$\mathrm{df}=438 ; * * \mathrm{p}<0.01$

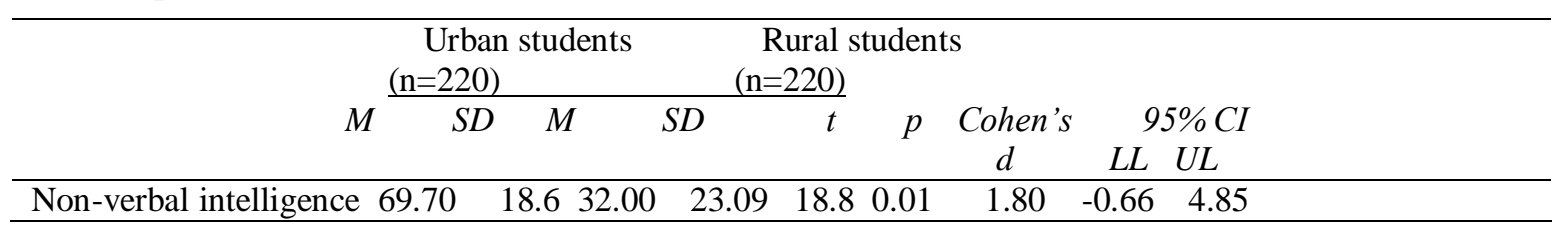

Table 1 shows the t-test values and analysis of the sample data of 440 students (i.e., 220 urban \& 220 rural) on non-verbal intelligence. It reveals that there is significant difference between the non-verbal intelligence of urban and rural students $(\mathrm{t}=18.8 ; \mathrm{df}=438 ; * \mathrm{p}<0.01)$. 
Table 2

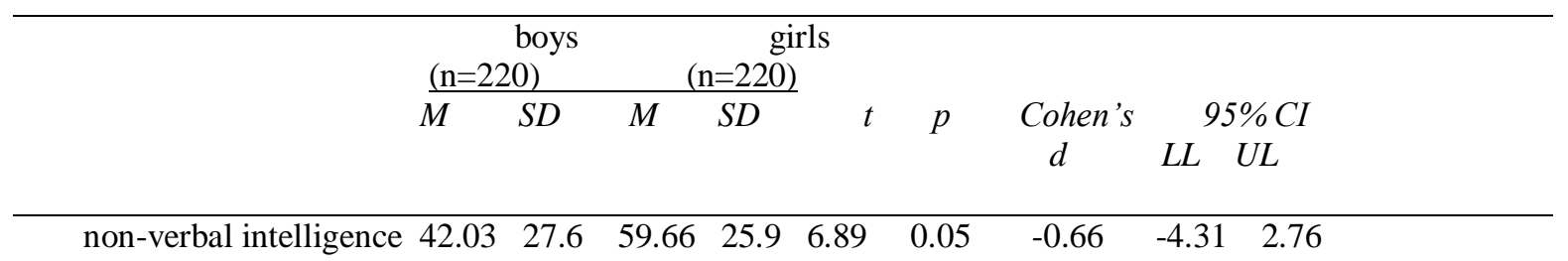

\footnotetext{
Mean, Standard Deviation and t-test of boys and girls (both rural \& urban areas) on Non verbal Intelligence $\mathrm{df}=438 ; * \mathrm{p}<0.05$
}

Table 2 shows the t-test values and analysis of the sample data of 440 students (i.e., 220 boys \& 220 girls) on non-verbal intelligence. It indicates the significant difference between the non-verbal intelligence of boys and girls of urban and rural areas $(\mathrm{t}=6.89 ; \mathrm{df}=438 ; * \mathrm{p}<0.05)$.

Table 3

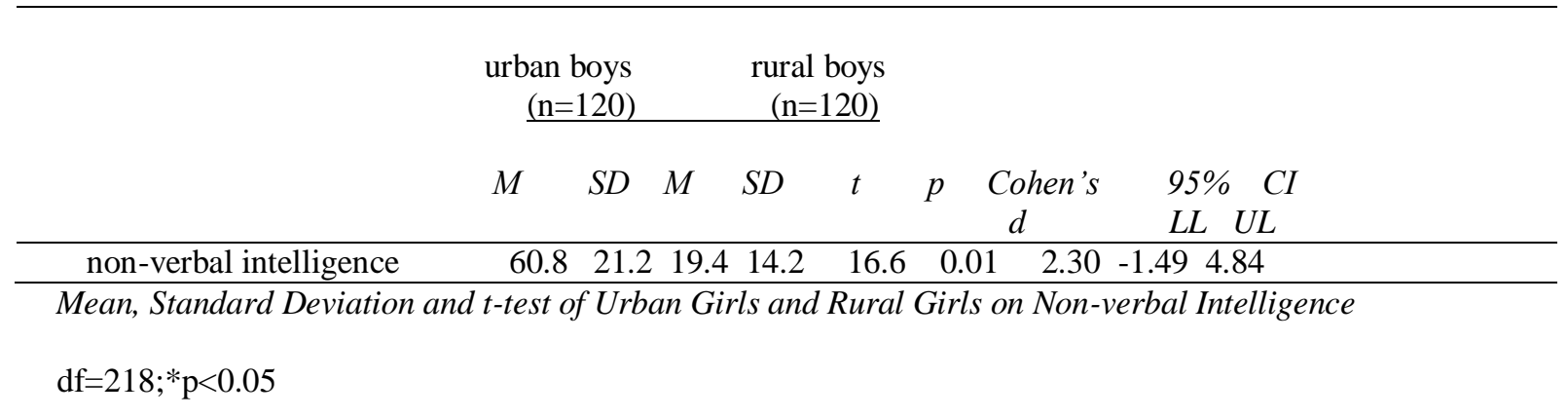

Table 3 reveals the t-test values and analysis of the sample data of 220 girls (i.e., 120 urban girls \& 120 rural girls) on non-verbal intelligence. It indicates the significant difference between the non-verbal intelligence of urban and rural girls $(\mathrm{t}=10.3 ; \mathrm{df}=218 ; * \mathrm{p}<0.05)$.

Table 4

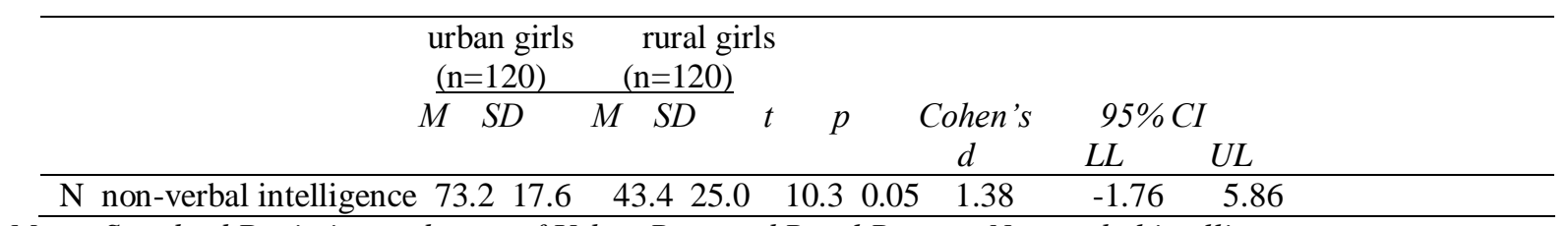

Mean, Standard Deviation and t-test of Urban Boys and Rural Boys on Non-verbal intelligence

$\mathrm{df}=218 ; * \mathrm{p}<0.01$

Table 4 indicates the t-test values and analysis of the sample data of 220 boys (i.e., 120 urban boys \& 120 rural boys) on non-verbal intelligence. It reveals the significant difference between the non-verbal intelligence of urban and rural boys $(\mathrm{t}=16.6 ; \mathrm{df}=218 ; * * \mathrm{p}<0.01)$.

\section{Discussion}

The findings of this study indicate that there is significant difference between the urban and rural students on Raven's Standard Progressive Matrices suggesting that urban students have high level of nonverbal intelligence as compared to rural students $(\mathrm{t}=18.8, \mathrm{df}=438, * * \mathrm{P}<.01)$ (Table 1$)$. Support comes from the study by Wysocki and Cankardas (2006) they administered the Raven's Progressive Matrices on Polish adults from different culture backgrounds of Poland. Results indicated that cultural background (rural \& urban), education, profession and age affect the IQ. Kowall, Watson and Madak (1990) showed that verbal IQ of urban children was comparably higher 
than Native children on WISC-R. Sternberg (2004) also claimed that culture is important aspect in order to define the intelligence. Rosselli and Ardila (2003) concluded that individual's culture can affect the performance on nonverbal tests such as copying figures, drawing maps or listening to tone. The present study is similar to the previous study conducted by Chan and Lynn (1989) that showed Chinese children obtain the IQ of 116 which is comparatively higher than the samples of Australia, Czechoslovakia, Germany, Romania, the UK and the US that obtain IQs in the range 95-102 that propose that the cultural difference exist in IQ. Nagoshi and Johnson (1985) also found the significant cultural differences on Wechsler Adult Intelligence Scale (WAIS) performance. Moreover, Park and Gallimore (1975) also found differences in cognitive style between rural and urban children in the Republic of Korea.

Studies on relationship between culture and intelligence showed the significance difference between the mean IQ of different cultures (e.g Bridgeman \& Buttram, 1975; Reynolds \& Jensen, 1983; Nagoshi \& Johnson, 1985; Palmer, Olivarez, Willson \& Fordyce, 1989; Lynn, Backhoff, \& Contreras, 2005). Stenberg and Grigorenko (2004) suggested that different cultural background can result in alteration of the meaning of intelligence because behavior that regard as positive in one environment is proves to be negative in another background.

In the second hypothesis it was assumed that boys have high level of non-verbal intelligence as compare to girls. The findings do not support the hypothesis $(\mathrm{t}=6.89$, * $\mathrm{p}<0.05)$ suggesting that girls have high level of nonverbal intelligence $(\mathrm{M}=59.66, \mathrm{SD}=25.9)$ as compared to boys $(\mathrm{M}=42.03, \mathrm{SD}=27.6)$ (Table 2). Present study has the support from the study of Pati and Dash (1990) that suggested girls performed better on Progressive Matrices (PMT) and Stroop Color and Word Test (SCWT) as compared to boys. Khaleefa and Lynn (2008) also proved in their study that girl's performance is comparatively better than boys on Colored Progressive Matrices in the United Arab Emirates. Present result is also similar to Lynn, Allik, Pullman, and Laidra (2004) who tested the gender differences in IQ by administering the Progressive Matrices on adults in Estonia and proved that IQ of girls of age 12-15 was high as compare to boys. Owen and Lynn (1993) also indicated that females gain significantly higher scores on perceptual speed and memory for meaning (except among the black sample).In addition, Colom and García-López (2002) indicated that female have higher score on PMA inductive reasoning test.

Support also comes from the study of Lynn and Mulhern (1991) who compared sex differences in the Scottish standardization sample of the Wechsler Intelligence Scale for Children Revised (WISCR) with those in the American standardization sample. And suggested that in both countries, females performed best on Coding followed by Digit Span. Lynn (1994) also proposed that among children up to the age of around 14 years the sex differences in intelligence are smaller because girls mature earlier than boys.

Spinath, Freudenthaler and Neubauer (2010) suggested that girls benefit even more than boys from a high level of verbal intelligence. The results of present study is similar to Roivainen (2011) who indicated that females have an benefit in processing speed tasks and also do better than males in reading and writing skills.

Support also comes from the study of Lrwing and Lynn (2005) who offered a meta-analysis of 22 studies on the Progressive Matrices. In the 8 studies of the SPM, females showed considerably larger variability. Geffen, Moar, O'hanlon, Clark, and Geffen (1990) also found that females performing better than males on Auditory Verbal Learning Test (AVLT). Sluis et al. (2006) investigated that females` performance was better than males on digit of symbol substitution. Herlitz and Yonker (2002) indicated that women scores high on the verbal episodic memory tasks and on face recognition as compared to male. Jausovec and Jausovec (2009) proposed that the females' have better visual event-categorization process as compared to males.

Present study is quite similar to the previous study of Rojahn and Naglieri (2006) who claimed that females scored higher between 10 and 13 years on Naglieri Nonverbal Ability Test (NNAT). Hedges and Nowell (1995) also examined gender differences in central tendency, variability and the scores on mental tests and indicated that females perform better on tests of reading comprehension and perceptual speed.

In the third hypothesis of the study it was assumed that urban girls have high level of non-verbal intelligence as compare to rural girls. Thus findings support the hypothesis $3(\mathrm{t}=10.3, * \mathrm{p}<0.05)$, it gets clear that urban girls have high level of nonverbal intelligence as compare to rural girls due to significant difference with mean scores of urban girls $(\mathrm{M}=73.2, \mathrm{SD}=17.6)$ and rural girls $(\mathrm{M}=43.4, \mathrm{SD}=25.0)$ (Table 3).Supports come from the study of Esfandiari and Jahromi (1989) who evaluate the intelligence and vocational aspiration of students in single-sex monolingual high schools with those in mixed-sex bilingual high schools. Findings demonstrated that girls from mixed-sex bilingual high schools had highest mean scores on Raven's test as compare to girls in singlesex monolingual high schools.

In the fourth hypothesis of the study it was assumed that urban boys have high level of non-verbal intelligence as compare to rural boys. Thus accept the hypothesis $4(\mathrm{t}=16.6, * * * \mathrm{p}<0.01)$, it gets clear that urban boys have high level of nonverbal intelligence as compare to rural boys due to significant difference with mean scores of 
urban boys $(\mathrm{M}=60.8 ; \mathrm{SD}=21.2)$ rural boys $(\mathrm{M}=19.4 ; \mathrm{SD}=14.2)$ (Table 4). Support come from the previous study of Valencia (1979) who administered the Raven Colored Progressive Matrices on Chicano and Anglo boys in order to compare the nonverbal intellectual performance. Difference was found between both ethnic groups as Anglo group scored higher than the Chicano group. The present study is also similar to the previous study of Rangari (1987 as cited in Ghamri, 2012) who studied the intelligence of the tribal and the non-tribal students of eleventh and twelfth standards. Findings indicated that the non-tribal students perform better in intelligence than the tribal students. Furthermore, the non-tribal males and the non-tribal urban students were higher in intelligence than their tribal counterparts. But the non-tribal females and the non-tribal rural students are same as tribal students.

Support also comes from previous study of Murray, Waites, Veldman, and Heatly (1973) who investigated the patterns of I.Q scores of 2498 delinquent boys of different ethnic groups on the WISC and WAIS. Results showed that the mean I.Q scores of the various ethnic groups were spread over a 15-point range with Anglos highest and blacks lowest.

Lynn (2004) also argued that Jews have a higher average level of verbal intelligence than non-Jewish whites. Scores of Jews, non-Jewish whites and blacks were compared. Result indicated that Jews obtained high scores as compare to non-Jewish whites.

\section{Conclusion}

This study was conducted to measure the level of non-verbal intelligence among the urban and rural school students. Urban and rural school students were taken as a sample. On the basis of obtained findings, it is concluded that non-verbal intelligence of urban students (either boys or girls) is better than rural school students. Study indicated that girls have high level of non-verbal intelligence as compare to boys. Findings proved that girls of urban areas have significantly high IQ as compare to rural girls. Results also suggested that boys of urban schools are likely to have high level of non-verbal intelligence as their rural counterpart.

\section{References}

[1]. Abdel-Khalek, A. M. (1988). Egyptian results on the standard progressive matrices, Personality and Individual Differences, 9(1), 193195. doi:1.1016/ 0191-8869(88)90051-7

[2]. Alexopoulos, D. S. (1997). Urban vs Rural Residence and IQ. Psychological Reports, 80(3), 851-860.doi: 10.2466/pr0.1997.80.3.851

[3]. Boeree, C. G. (2003) Intelligence and IQ. Retrieved from http://webspace.ship. edu/cgboer/intelligence.htm

[4]. Borkowski, J. G., \& Krause, A. (1983). Racial differences in intelligence: The importance of the executive system, Intelligence, 7(4), 379-395. doi:10.1016/0160-2896(83)90012-0

[5]. Cornoldi, C., Belacchi, C., Giofre, D., Martini, A., \& Tressoldi, P. (2010). The mean Southern Italian children IQ are not particularly low: A reply to R. Lynn, Intelligence, 38(5), 462-470. doi:10.1016/j.intell.2010.06.003

[6]. Colom, R., \& García-López, O. (2002). Sex differences in Fluid Intelligence among high school graduates, Personality and Individual Differences, 32(3), 445-451. doi:10.1016/S0191-8869(01)00040-X

[7]. Diaz, A., Sellami, K., Infanzon, E., Lanzon, T., \& Lynn, R. (2010). Sex Differences in Means and Variance of Intelligence: Some data for Spain, Mankind Quarterly, 210. Retrieved from http://www.docstoc.com/docs/7522 8628/

[8]. Fagan, J. F., \& Holland, C. R. (2002). Equal opportunity and racial differences in IQ, Intelligence, 30(4), 361-387. doi:10.1016/S01602896(02)00080-6

[9]. Fagan, J. F., \& Holland, C. R. (2007). Racial equality in intelligence: Predictions from a theory of intelligence as processing, Intelligence, 35(4), 319-334. doi:1 0.1 016/j. intell.2006.08.009

[10]. Gardezi, A. H. (2001). Development and standardization of an indigenous nonverbal test of intelligence. Retrieved from http://prr.hec.gov.pk/thesis/235 0.pdf

[11]. Geffen, G., Moar, K. J., O'hanlon, A. P., Clark, C. R., \& Geffen, L. B. (1990). Performance measures of 16 to 86 year old males and females on the auditory verbal learning test, Clinical Neurologist, 4(1), 45-63. doi: 10.1080/1385404 9008401496

[12]. Guo, B., Aveyard, P., \& Dai, X. (2009). The Chinese Intelligence Scale for Young Children Testing Factor Structure and Measurement Invariance Using the Framework of the Wechsler Intelligence Tests, Educational and Psychological Measurement, 69(3), 459-474. doi:10.1177/001316440933220 9

[13]. Herlitz, A., \& Yonker, J. E. (2002). Sex differences in episodic memory: the influence of intelligence, J Clin Exp Neuropsychology, 24(1), 107-14. Retrieved from http://www.ncbi.nlm.nih.gov/pub med/11935429

[14]. Hedges, L. V., Nowell, A. (1995). Sex differences in mental test scores, variability, and numbers of high-scoring individuals, Science, 269(5220), 41-45. doi:10.1126/science.7604277

[15]. Jausovec, N., \& Jausovec, K. (2009). Gender related differences in visual and auditory processing of verbal and figural tasks, Brain Research, 1300, 135-145.doi:10.1016/j.brainres.2009.08.093

[16]. Kaniel, S., \& Fisherman, S. (1991). Level of performance and distribution of errors in the progressive matrices test: A comparison of Ethiopian and Israeli adolescents. International Journal of Psychology, 26, 25-33. doi: 10.1080/00 207599108246847

[17]. Khaleefa, O., \& Lynn, R. (2008). Sex Differences on the Progressive Matrices: Some Data from Syria, Mankind Quarterly, 48 (3), $345-$ 351. Retrieved from http://www.mankindquarterly.org/spring2008 khaleefa.html

[18]. Lrwing, P., \& Lynn, R. (2005). Sex differences in means and variability on the progressive matrices in university students: A metaanalysis, British Journal of Psychology, 96(4), 505-524. doi: 10.1348/000712605X53542

[19]. Liu, J., \& Lynn, R. (2011). Factor structure and sex differences on the Wechsler Preschool and Primary Scale of Intelligence in China, Japan and United States, Personality and Individual Differences, 50(8), 1222-1226. doi:10.10 16/j .paid.2011.02.013 
[20]. Lynn, R. (1994). Sex differences in intelligence and brain size: A paradox resolved, Personality and Individual Differences, 17(2), 257271. doi:10.101 6/0191-8869(94)90030-2

[21]. Lynn, R., Allik, J., Pullman, H., \& Laidra, K. (2004). Sex differences on the progressive matrices among adolescents: Some data from Estonia, Personality and Individual Differences, 36, 1249-1255.doi: 10.1016/S0191-8869(02)00 240-4

[22]. Lynn, R. (2004). The intelligence of American Jews, Personality and Individual Differences 36, (1) 201-206 doi:10.1016/S0191$8869(03) 00079-5$

[23]. Lynn, R. (2009). Fluid intelligence but not vocabulary has increased in Britain, 1979-2008, Intelligence, 37(3), $249-255$. doi:10.1016/j.intell.2008.09.007

[24]. Lynn, R., \& Mulhern, G. (1991). A comparison of sex differences on the Scottish and American standardisation samples of the WISC-R, Personality and Individual Difference , 12(11), 1179-1182. doi: http://dx.doi.org/10.1016/01 91-8869(91)90082-M

[25]. Lynn, R., Backhoff, E., \& Contreras-Nino, L. (2004). Sex differences on g, reasoning and visualisation tested by the progressive matrices among 7-10 year olds: some normative data for Mexico779-787, Personality and Individual Differences, 36(4), doi: 10.1016/S01918869(03)00132-6

[26]. MacAvoy, J., Orr, S., \& Sidles, C. (1993). The raven matrices and navajo children: normative characteristics and culture fair application to issues of intelligence, giftedness, and academic proficiency, Journal of American Indian Education, 33(1), 32-43. Retrieved from http://www.eric.ed.gov

[27]. Murray, M. E., Waites, L., Veldman, D. J., \& Heatly, M. D. (1973). Ethnic Group Differences between WISC and WAIS Scores in Delinquent Boys, The Journal of Experimental Education, 42(2), 68-72. Retrieved from http://www .jstor.org/stable/20150933

[28]. Murray, M. E., Waites, L., Veldman, D. J., \& Heatly, M. D. (1973). Ethnic Group Differences between WISC and WAIS Scores in Delinquent Boys, The Journal of Experimental Education, 42(2), 68-72. Retrieved from http://www .jstor.org/stable/20150933

[29]. Naderi, H., Abdullah, R., Aizan, H, T., \& Sharir, J. (2010). Intelligence and academic achievement: an investigation of gender differences, Life Science Journal, 7 (1), 83-87. Retrieved from http://www.sciencepub.net

[30]. Powers, S., \& Barkan, J. H. (1986). Concurrent Validity of the standard progressive matrices for Hispanic and nonHispanic and seventhgrade students, Psychology in the Schools, 23(3), 333-336. doi:10.1002/1520-6807(198610)23:4<333

[31]. Rojahn, J., \& Naglieri, J. A. (2006). Developmental Gender Differences on the Naglieri Nonverbal Ability Test in a Nationally Normed Sample of 5-17 Year Olds Intelligence, 34 (3), 253-260.doi:10.1016/j.intell.2005.09.004

[32]. Roivainen, E. (2011). Gender differences in processing speed: A review of recent research, Learning and Individual Differences, 21(2), 145-149. doi:10.1016/ j.lindif.2010.11.021

[33]. Rushton, J. P., Cvorovic, J., \& Bons, T. A. (2007). General mental ability in South Asians: Data from three Roma (Gypsy) communities in Serbia, Intelligence, 35(1), 1-12.doi:10.1016/j.intell.2006.09.002

[34]. Sluis, S. van, der., Posthuma, D., Dolan, $\quad$ C.V., $\quad$ Geus, $\quad$ E.J.C. $\quad$ de., Colom, R., \& Boomsma, D.I.(2006). Sex differences on the Dutch WAIS-III, Intelligence, 34(3), 273289.doi: $10.1016 /$ j.intell.2005.08.002

[35]. Spinath, B., Freudenthaler, H.H., \& Neubauer, A. C. (2010). Domain-specific school achievement in boys and girls as predicted by intelligence, personality and motivation, Personality and Individual Difference, 48(4), 481-486. doi:10.1016/j.paid.2009.11.028

[36]. Sternberg, R. J., \& Grigirenko, E. L. (2004). Intelligence and Culture: How Culture Shapes What Intelligence Means, and the Implications for a Science of Well-Being, Philosophical Transactions: Biological Sciences, 359(1449), $1427-1434$. doi: $10.1098 /$ rstb.2004.1514

[37]. Swami, V., \& Furnham, A. (2010). Self-assessed intelligence: Inter-ethnic, rural- urban, and sex differences in Malaysia, Learning and Individual Differences, 20(1), 51-55. doi:10.1016/j.lindif.2009.11.002

[38]. Te Nijenhuis, J., De Jong, M. J., Evers, A., \& van der Flier, H. (2004). Are cognitive differences between immigrant and majority groups diminishing? European Journal of Personality, 18, 405-434. doi:10.1002/per.511

[39]. Thangavel, N. (1986). A study of sex differences on Seguin Form Board Test, Child Psychiatry Quarterly, 19(4), 158-160. Retrieved from http://psycnet .apa.org/psycinfo/1988-10245-001

[40]. Valencia, R.R. (1979). Comparison of intellectual performance of Chicano and Anglo third-grade boys on the Raven Coloured Progressive Matrices, Psychology in the Schools, 16(3), 448-453. doi: 10.1002/1520-6807(197907 )16:3<448::AIDPITS2310160326>3.0.CO;2-Z

[41]. Valencia, R.R. (1984). Reliability of the Raven Coloured Progressive Matrices for Anglo and for Mexican-American children, Psychology in the Schools, 21(1), 49-52. doi: 10.1002/1520-6807(198401)21:1<49::AID-PITS2 310210109>3.0.CO;2-H

[42]. Vincent, K. R., \& Cox, J. A. (1974). A re-evaluation of Raven's Standard Progressive Matrices, Journal of Psychology: Interdisciplinary and Applied, 88(2), 299-303. doi:10.1080/00223980.1974.9915740

[43]. Wysocki, B. A., \& Cankardas, A.(2006). A new estimate of Polish intelligence, Journal of Educational Psychology, 48(8). 525533doi:10.1037/h0041737 